\title{
Com són i què fan els científics segons els nens i les nenes d'El 5 anys
}

\author{
Elena Casadevall i Iracema Roig, mestres d'Educació Infantil \\ ecasadevall@escolasadako.com, iroig@escolasadako.com \\ Regina Civil, cap del Departament de Ciències Experimentals \\ rcivil@escolasadako.com \\ Escola Sadako, Barcelona
}

La publicació del llibre El Científic dibuixat per l'Observatori de la Difusió de la Ciència ens va portar a esbrinar quina percepció tenen els nostres nens i nenes d'Educació Infantil 5 anys de les persones que es dediquen professionalment a la ciència. L'experiència que presentem recull els passos i els resultats del nostre estudi.

Paraules clau: educació infantil, científic/a, modes comunicatius, setmana de la ciència

El curs escolar 2009-2010, durant la Setmana de la Ciència i animades per la nostra Cap de Departament, les mestres d'EI5 hem fet un treball amb els nens i les nenes amb l'objectiu de saber quina opinió tenen de la figura dels científics i les científiques.

\section{Objectius}

- Qüestionar-se coses

- Escoltar i observar amb curiositat

- Formular preguntes sobre la informació rebuda i anticipar respostes

- Representar gràficament el procés seguit en l'exploració i adquisició de nou coneixement

- Pensar i crear

L'activitat es recolza en el llibre El Científic dibuixat, ha durat una setmana i s'ha dividit en els següents apartats.

\section{Motivació a l'aula}

\section{a) Conversa inicial}

Les mestres preguntem als nens i les nenes què pensen que és un científic, com se l'imaginen i què creuen que fa en la seva feina. Hem de dir que la majoria de nens no coneixen el mot "científic" i per tant no saben què respondre. Els pocs nens i nenes que ho fan diuen:

Els científics i les científiques...

- van vestits de color blanc

- treballen en hospitals

- miren si les coses suren o no suren

- espien

- porten ulleres

- tenen coses com els indis per tallar llenya...

A les respostes apareixen alguns dels estereotips assignats a les persones que es dediquen a la ciència (bata blanca, ulleres) per l'alumnat i també per la societat en general.

\section{b) Conferències}

Es convida els pares i les mares a participar de l'experiència. Per fer-ho es demana que algun pare o mare que treballi com a científic o científica vingui a l'escola a fer una conferència als nens i les nenes i els expliqui en què consisteix el seu treball. Es rep resposta de:

- un astrònom

- un enginyer que fa recerca en tractament digital de la imatge i que es presenta als nens i nenes com a matemàtic

- un químic 
En dies separats vénen a fer la seva presentació els dos primers pares i tots dos s'ajuden de suport audiovisual per a les seves ponències. El pare astrònom projecta imatges de diferents astres (fig. 1), entre els quals el Sol i els planetes del sistema solar, ben coneguts pels infants, i el pare matemàtic explica, entre altres coses, com es fa un dibuix animat, com les imatges digitals estan formades per punts i com es pot modificar i millorar una imatge envellida (fig. 2).

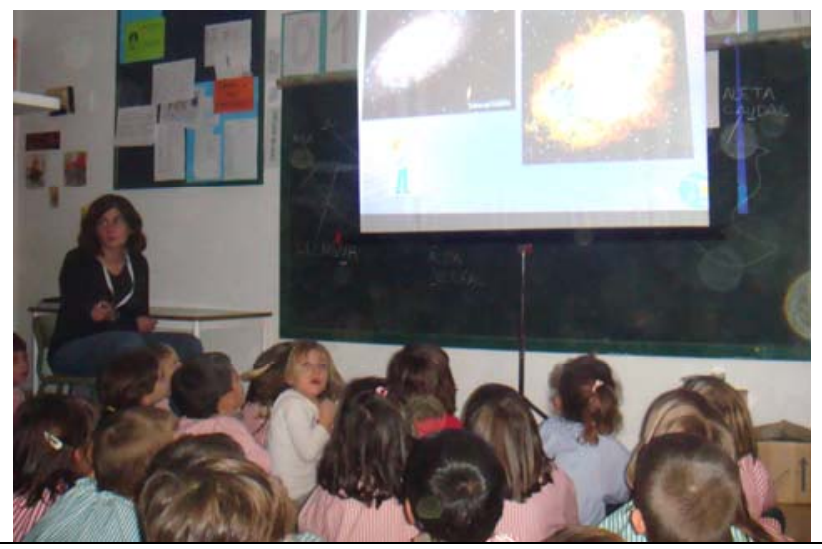

Figura 1. Presentació del pare astrònom.

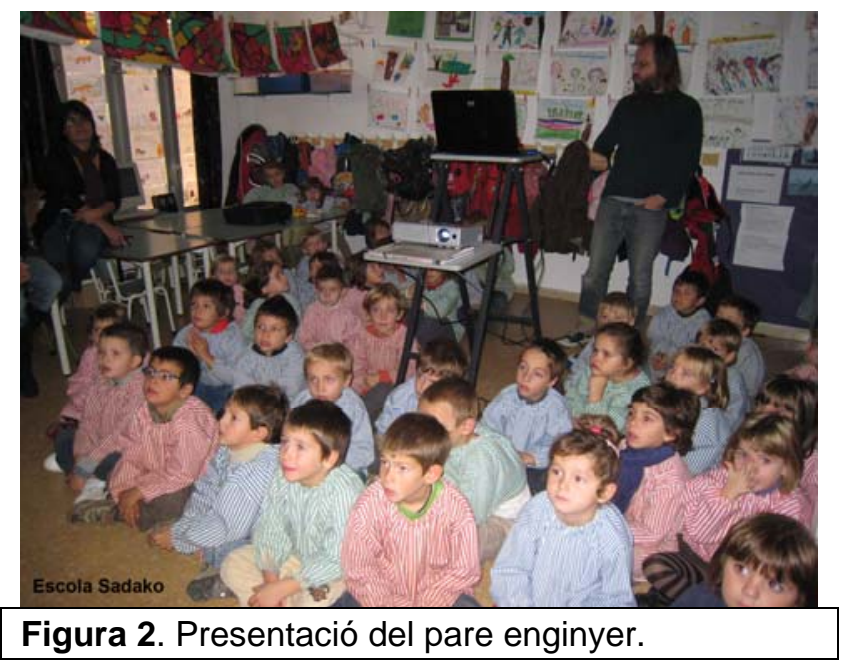

Les diapositives mostren tant els instruments que fan servir per treballar com els resultats de les seves investigacions. Després de cada audiovisual s'estableix un col-loqui on nens i nenes fan les preguntes que volen als científics.

El pare químic finalment no pot venir però explica alguna de les activitats pròpies d'un químic al seu fill i és aquest qui, al seu torn, ho explica als companys, ajudat per la mestra.
El nen arriba a escola amb tot el material necessari per fer la presentació i es pren molt seriosament la responsabilitat que el pare li ha delegat. Fa la seva explicació vestit com un químic i amb alguns dels instruments de laboratori que el pare li ha deixat (figs. 3 i 4).

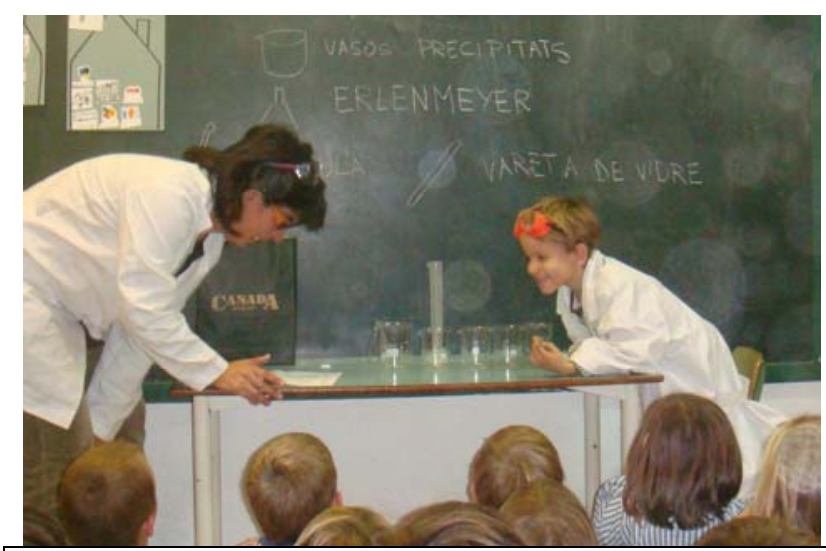

Figura 3. El nen i la mestra preparen el material del treball químic.

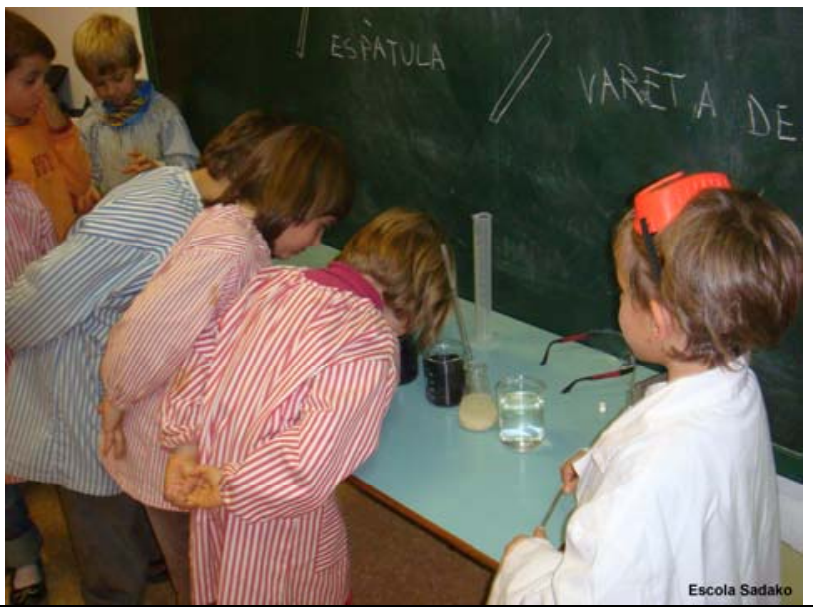

Figura 4. Companys i companyes passen a observar el resultat dels experiments.

Vesteix la bata blanca de laboratori del pare, que li va molt gran i el fa estar molt graciós, i unes ulleres de joguina que imiten les de seguretat del laboratori. Ensenya el material de laboratori i explica com un professional les mescles que prepara.

Aquí també, el grup classe fa preguntes al company "químic" al final de l'exposició i, en acabar, les mestres preguntem als nens i a les nenes què han entès i què han après. 


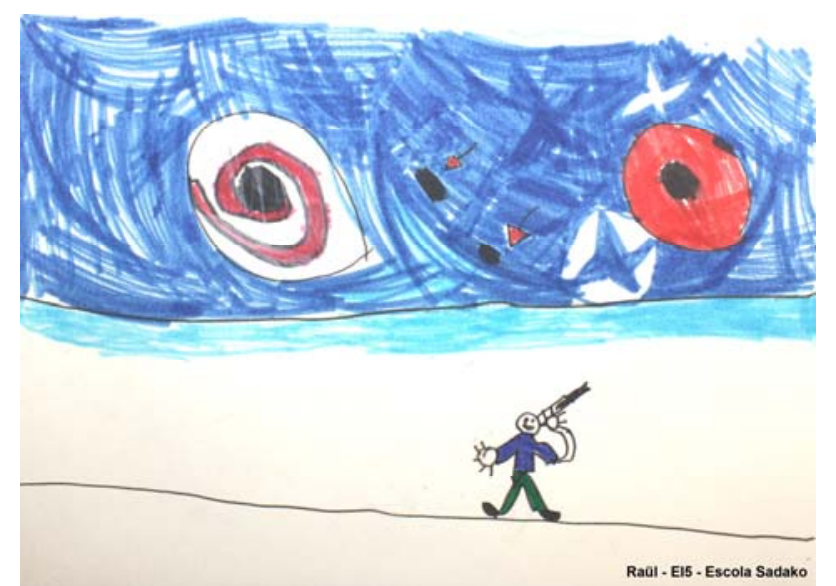

Figura 5. Astrònom observant el cel.

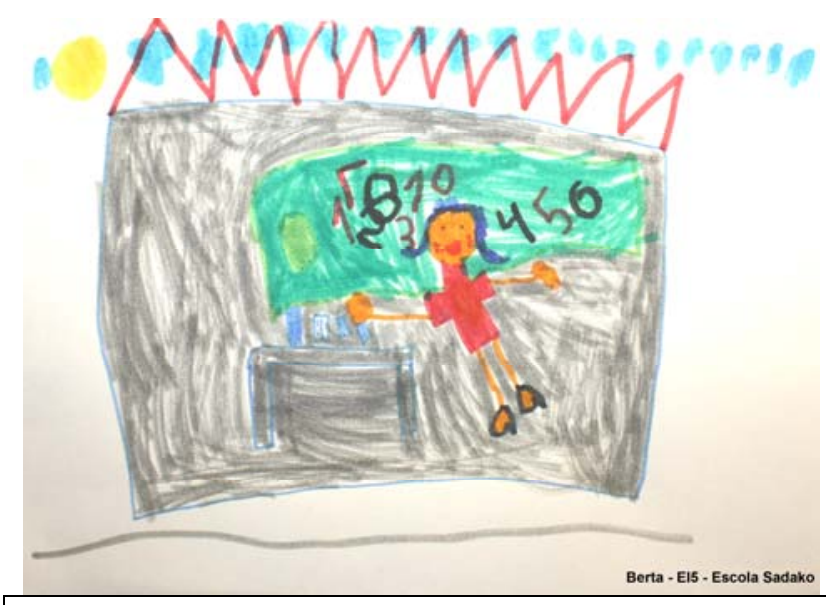

Figura 7. Combinació de les tres disciplines presentades: astronomia, matemàtiques i química.

Ara ha canviat el nivell de participació, tots els nens i nenes poden i volen intervenir-hi. Tots han après alguna cosa sobre la figura del científic. Es recullen les respostes, entre altres:

Els científics....

- han de portar bata

- necessiten ulleres

- es disfressen

- tenen prismàtics i telescopis

- fan experiments

- treballen amb colors, amb l'ordinador

- ens diuen que nosaltres no podem mirar el sol

- han de saber matemàtiques

- han de tenir el material per fer experiments

- necessiten pensar molt i el més important de tot són els ulls per observar

- amb els ulls no arriben a veure les galàxies i han de fer servir telescopis molt potents

- els científics treballen amb la ciència...

S'observa que les respostes reflecteixen el contingut de les tres conferències.

\section{Avaluació}

S'avalua molt positivament l'experiència. Els nens i les nenes han mostrat un gran interès i s'han engrescat en un tema que els era desconegut. A més, l'activitat ha servit a molts d'ells per descobrir la feina o ocupació del pare i de la mare. Ens hauria agradat comptar amb la participació d'alguna mare científica però no ha pogut ser.

Un cop acabada l'activitat pensem que potser hauríem d'haver fet la proposta de demanar als infants un dibuix previ per poder-lo comparar amb 
el que fan després de les conferències. Tot i això, havent comprovat que no saben el significat de la paraula "científic", potser no ens seria gaire útil aquest dibuix previ ja que segurament els n'hauríem d'haver explicat el significat i aleshores els seus dibuixos estarien "tenyits" per les nostres paraules.

\section{Bibliografia}

ESCALAS, M.T., RUIZ, I., ZORRILLA, J. (coord.) i al. (2009). El Científic dibuixat. Un llibre per pensar, descobrir i dibuixar. UAB: Observatori de la Difusió de la Ciència. 